\title{
Old subjects with sepsis in the emergency department: trend analysis of case fatality rate
}

\author{
Andrea Fabbri ${ }^{1 *}$ (D), Giulio Marchesini ${ }^{2}$, Barbara Benazzi ${ }^{1}$, Alice Morelli ${ }^{1}$, Danilo Montesi ${ }^{3}$, Cesare Bini ${ }^{4}$ and \\ Stefano Giovanni Rizzo ${ }^{5}$
}

\begin{abstract}
Background: The burden of sepsis represents a global health care problem. We aimed to assess the case fatality rate (CFR) and its predictors in subjects with sepsis admitted to a general Italian hospital from 2009 to 2016, stratified by risk score.

Methods: We performed a retrospective analysis of all sepsis-related hospitalizations after Emergency Department (ED) visit in a public Italian hospital in an 8-year period. A risk score to predict CFR was computed by logistic regression analysis of selected variables in a training set (2009-2012), and then confirmed in the whole study population. A trend analysis of CFR during the study period was performed dividing patient as high-risk (upper tertile of risk score) or low-risk.

Results: Two thousand four hundred ninety-two subjects were included. Over time the incidental admission rate (no. of sepsis-related admissions per 100 total admissions) increased from 4.1\% (2009-2010) to 5.4\% (2015-2016); $P<0.001$, accompanied by a reduced CFR (from 38.0 to 18.4\%; $P<0.001$ ). A group of 10 variables (admission to intensive care unit, cardio-vascular dysfunction, HIV infection, diabetes, age $\geq 80$ years, respiratory diseases, number of organ dysfunction, digestive diseases, dementia and cancer) were selected by the logistic model to predict CFR with good accuracy: AUC 0.873 [0.009]. Along the years CFR decreased from 31.8\% (2009-2010) to 25.0\% (20152016); $P=0.007$. The relative proportion of subjects $\geq 80$ years (overall, $52.9 \%$ of cases) and classified as high-risk did not change along the years. CFR decreased only in low-risk subjects (from 13.3 to 5.2\%; $P<0.001$ ), and particularly in those aged $\geq 80$ (from 18.2 to $6.6 \% ; P=0.003$ ), but not in high-risk individuals (from 69.9 to $64.2 \% ; P=0.713$ ).
\end{abstract}

Conclusion: Between 2009 and 2016 the incidence of sepsis-related hospitalization increased in a general Italian hospital, with a downward trend in CFR, only limited to low-risk patients and particularly to subjects $\geq 80$ years.

Keywords: Sepsis, Elderly, Case fatality rate, Risk score, Trend, Emergency department

\section{Introduction}

The elderly population is considered to be at high-risk for sepsis, due to multiple comorbidities, frailty, repeated or prolonged hospitalizations $[1,2]$ with a worsening outcome. Large nationwide registries indicate that up to $60 \%$ of patients with sepsis are over 65 , with a positive trend for diagnosis of $1.5 \%$ per year [3], with particular relevance in subjects $\geq 80$ years [2]. Epidemiological studies also showed

\footnotetext{
* Correspondence: andrea.fabbri@auslromagna.it

${ }^{1}$ Emergency Department, Presidio Ospedaliero Morgagni-Pierantoni, AUSL

della Romagna, via C. Forlanini 34, 47121 Forli, FC, Italy

Full list of author information is available at the end of the article
}

an increased incidence of diagnoses following the implementation of clinical guidelines, with decreased mortality [4].

Old patients with sepsis, compared with adults may differ in several aspects: the primary sites of infection and organ system dysfunction may be different, which may have an impact on the final outcome [5]. In the presence of an increased number of diagnoses, it is not known whether the clinical characteristics and the case fatality rate (CFR) of elderly subjects with sepsis-related hospitalizations are decreasing at a similar rate as observed in the adult population [3].Aim of the study was to evaluate the association between the main characteristics and CFR of sepsis-

(c) The Author(s). 2019 Open Access This article is distributed under the terms of the Creative Commons Attribution 4.0 International License (http://creativecommons.org/licenses/by/4.0/), which permits unrestricted use, distribution, and reproduction in any medium, provided you give appropriate credit to the original author(s) and the source, provide a link to the Creative Commons license, and indicate if changes were made. The Creative Commons Public Domain Dedication waiver (http://creativecommons.org/publicdomain/zero/1.0/) applies to the data made available in this article, unless otherwise stated. 
related hospital admissions of older subjects in a general Italian hospital, in a trend analysis between 2009 and 2016.

\section{Methods}

\section{Study design}

In a chart review analysis we included all adult sepsis-related hospitalizations in the District hospital of Forlì (FC), Italy from 2009 to 2016 as defined by Angus et al [6]. In ED an electronic warning system is available (Systemic Inflammatory Response syndrome - SIRS) [7] for the early detection of patients at high risk of sepsis since 2007. The final diagnosis was derived from hospital discharge codes (see below).

\section{Registry data}

The community hospital has a total capacity of 463 beds; during the 8-year study period, over 55,000 cases were hospitalized after ED visit for surgical and medical diseases out of 170,000 admissions. The hospital database is directly connected with the General Registry Office of the District. The study was approved by the ethical committee of CEROM Romagna, Italy (2299/2019/O/OssN, January 16, 2019).

\section{Study population}

The study included any subject with ICD9-CM code for both bacterial and fungal infections and acute organ dysfunction with a code extraction method according to the 3-rd International Consensus definition for sepsis (Sepsis-3) $[8,9]$. As the study period predated the 2016 definitions [6], sepsis patients were defined by any ICD9$\mathrm{CM}$ codes for both bacterial and fungal infections and acute dysfunction as previously suggested [10, 11]. In order to include all cases, we also included cases explicitly coded as severe sepsis (995.92) or septic shock (785.52), in accord with the previous definition of ED sepsis. This approach was accepted as compatible with the 3rd International Consensus definition for sepsis (SEPSIS-3) [9].All information extracted by diagnosis codes where then matched with key information recorded at ED arrival, also in cases where diagnosis of sepsis was not suspected at time of ED presentation.

\section{Data variables}

Selected variables for the analyses were demographic characteristics, main comorbid conditions, serious infection diagnoses, and organ dysfunction diagnoses. Other key pieces of information were the mode of arrival in ED, triage vital signs, SIRS score $\geq 2$, ED waiting time, ED length-of-stay, type of serious infection diagnosis codes and organ dysfunction diagnosis codes, intensive care Unit (ICU) admission.

Data abstractors identified up to 5 documented diagnoses for each patient by ICD9-CM codes. In-hospital case fatality rate (CFR, i.e., the proportion of all-cause mortality) was verified by a linked local death certificate database and considered for the prognostic model.

\section{Statistical analysis}

The characteristics and outcomes of patients were compared across the 8-year study period. Mean value, standard deviation, median, interquartile range, number of cases, percent with $95 \%$ confidence interval was used to describe data distribution. Fisher's exact test for categorical variables and Student t-test for continuous variables were used to compare variables between groups.

The variables tested for multivariable analyses were: age, sex, arrival by emergency medical service, SIRS at entry, location at admission (ICU vs. ordinary ward), length of ED stay, and diagnoses codes of serious infection and organ dysfunction. Associated diseases were also considered, as measured by Charlson's Index [8] calculated on the basis of the main comorbidities, in particular diabetes mellitus (DM), chronic obstructive pulmonary disease (COPD), chronic kidney disease (CKD), history of acute heart failure (AHF), dementia, cancer, HIV infection.

A multivariable model was developed by stepwise forward analysis of factors considered significant in univariable analysis and according to clinically relevant predictors. To reduce the over fitting effect of the variables in an 8-year study period, data from the entire database were separated in two different periods for model building in the training set $(2009-2012 ; N=984)$ and then validated in the remaining cases. Since the analysis did not produce any difference in the ROC curve, the values of the training set were applied to the whole cohort. For the model building part of the analysis, the variables were selected on the basis of previous reports and a putative association with main outcome measures, in particular CFR. As it is recommended that covariates be introduced generously into the model, we included a large number $(N=27)$ of covariates independently of significance thresholds or other selection criteria. The full list of covariates can be found in Tables 1 and 2. The colinearity of combination of variables was tested by the variation inflation factors $(<2$, not significant). The accuracy of the scoring system was determined by calculating the area under the receiver operating characteristic (ROC) curve with standard error. A prognostic model was also performed to define factors associated with all cause CFR. ROC curves were compared by DeLong test.

Temporal trends of incidence and outcome were calculated as the rate difference between 2009 and 2016. Trends were tested by Poisson distribution analysis and represented by line graphs as mean with $95 \%$ confidence intervals.

In the analyses subjects were stratified by different risk categories (high-risk - upper tertile; low-risk - lower $2 / 3$ of cases of cases) on the basis of the coefficient computed in the logistic model. Two-tailed $P$ values $<0.05$ 
Table 1 Characteristics of patients with diagnosis of sepsis in relation to age (2009-2016). Data reported as number of cases and percent and mean and [standard deviation]

\begin{tabular}{|c|c|c|c|c|}
\hline Characteristics & All Cases & $<80$ years & $\geq 80$ years & OR $(95 \% \mathrm{Cl})$ or $\mathrm{P}$ value \\
\hline Age group & 2492 & $1173(47.1)$ & $1319(52.9)$ & $1.11(1.03-1.19)$ \\
\hline Sex (male \%) & $1355(54.4)$ & $672(57.3)$ & $683(51.8)^{*}$ & $0.80(0.68-0.94)$ \\
\hline Age (years, mean [SD]) & $77.9[14.6]$ & $66.5[12.4]$ & $88.1[6.8]^{*}$ & $<0.001$ \\
\hline \multicolumn{5}{|l|}{ Comorbidities } \\
\hline Diabetes & $727(29.2)$ & $300(25.6)$ & $427(32.4)^{*}$ & $1.39(1.17-1.66)$ \\
\hline COPD & $1142(45.8)$ & $474(40.4)$ & $668(50.6)^{*}$ & $1.51(1.29-1.77)$ \\
\hline CKD & 837 (33.6) & $366(31.2)$ & $471(35.7)^{*}$ & $1.22(1.04-1.45)$ \\
\hline $\mathrm{AHF}$ & $885(35.5)$ & $358(30.5)$ & $538(40.8)^{*}$ & $1.56(1.33-1.85)$ \\
\hline Dementia & $750(30.1)$ & $213(18.2)$ & $537(40.7)^{*}$ & $3.19(2.66-3.82)$ \\
\hline Cancer & $1046(42.0)$ & $525(44.8)$ & $521(39.5)^{*}$ & $0.81(0.69-0.94)$ \\
\hline HIV infection & $24(1.0)$ & $2(0.2)$ & $22(1.9)^{*}$ & $0.79(0.19-0.34)$ \\
\hline \multicolumn{5}{|l|}{ Vial Signs at ED arrival } \\
\hline Body temperature $\mathrm{C}$ & $37.6(0.8)$ & $37.7(0.8)$ & $37.5(0.7)^{*}$ & $<0.001$ \\
\hline Heart rate (beats/min) & $97.2(19.6)$ & $98.2(19.6)$ & $96.3(19.6)^{*}$ & 0.016 \\
\hline Systolic blood pressure (mmHg) & $117.5(24.0)$ & $117.2(23.0)$ & $117.9(24.8)$ & 0.464 \\
\hline Respiratory rate (breaths/min) & $23.1(5.8)$ & $22.9(5.9)$ & $23.2(5.8)$ & 0.201 \\
\hline $\mathrm{qSOFA} \geq 2$ & $2302(92.4)$ & $1103(94.0)$ & $1199(90.9)^{*}$ & $0.63(0.47-0.86)$ \\
\hline $\operatorname{SIRS} \geq 2$ & $1878(75.4)$ & $886(75.5)$ & $992(75.2)$ & $0.98(0.82-1.18)$ \\
\hline Diagnosis at admission & $819(32.9)$ & $350(29.8)$ & $469(35.6)^{*}$ & $1.30(1.10-1.53)$ \\
\hline
\end{tabular}

COPD Chronic obstructive pulmonary disease, CKD Chronic kidney disease, AHF Acute heart failure, HIV Human immune-deficiency virus, $q S O F A$, quick Sequential Organ Dysfunction Assessment, SIRS Systemic Inflammatory Response Syndrome. * significant difference vs. subjects $<80$ years, $P<0.05$

Table 2 Characteristics of subjects with sepsis related hospitalizations, grouped by age

\begin{tabular}{|c|c|c|c|c|}
\hline \multirow[t]{2}{*}{ Variables } & All Cases & $<80$ years & $\geq 80$ years & Odds Ratio \\
\hline & $n=2492$ & $n=1173$ & $n=1319$ & $(95 \% \mathrm{Cl})$ \\
\hline \multicolumn{5}{|l|}{ Serious Infection Diagnosis } \\
\hline Infection/parasitic & $233(9.3)$ & $153(13.0)$ & $90(6.8)^{*}$ & $0.49(0.37-0.64)$ \\
\hline Nervous system & $86(3.5)$ & $57(4.9)$ & $29(2.2)^{*}$ & $0.44(0.28-0.69)$ \\
\hline Circulatory system & $88(3.5)$ & $42(3.6)$ & $46(3.5)$ & $0.97(0.64-1.49$ \\
\hline Respiratory system & $1597(64.1)$ & $640(54.6)$ & $957(72.6)^{*}$ & $2.20(1.86-2.60)$ \\
\hline Digestive system & $281(11.3)$ & $153(13.0)$ & $128(9.7)^{*}$ & $0.72(0.56-0.92)$ \\
\hline Genitourinary system & $658(26.4)$ & $312(26.6)$ & $346(26.2)$ & $1.01(0.93-1.10)$ \\
\hline Pregnancy / puerpuerium & $5(0.2)$ & $1(0.1)$ & $4(0.3)$ & $3.60(0.40-31.9)$ \\
\hline Skin and subcutaneous tissue & $41(1.6)$ & $21(1.8)$ & $20(1.5)$ & $0.84(0.45-1.87)$ \\
\hline Muscular-skeletal system & $62(2.5)$ & $35(3.0)$ & $27(2.0)$ & $0.68(0.41-1.13)$ \\
\hline Other & $84(3.4)$ & $41(3.5)$ & $43(3.3)$ & $0.93(0.60-1.44)$ \\
\hline \multicolumn{5}{|l|}{ Organ Dysfunction Diagnosis } \\
\hline Cardiovascular & $677(27.2)$ & $281(24.0)$ & $396(30.0)^{*}$ & $1.36(1.14-1.63)$ \\
\hline Hematologic & $75(3.0)$ & $46(3.9)$ & $29(2.2)^{*}$ & $0.55(0.44-0.88)$ \\
\hline Hepatic & $55(2.2)$ & $32(2.7)$ & $23(1.7)$ & $0.63(0.37-1.09)$ \\
\hline Neurologic & $67(2.7)$ & $45(3.8)$ & $22(1.7)^{*}$ & $0.42(0.25-0.71)$ \\
\hline Renal & $433(17.4)$ & $197(16.8)$ & $236(17.9)$ & $1.08(0.88-1.33)$ \\
\hline Pulmonary & 1305 (52.4) & $542(46.2)$ & $763(57.8)^{*}$ & $1.60(1.36-1.87)$ \\
\hline
\end{tabular}


were considered statistically significant. The Statistical Package performed statistical analyses for the Social Science SPSS/PC+ (20.0 edition). The permission to access the medical records was granted by the ethical committee of Romagna (CEROM), Italy (424/2019), considering the observational and retrospective nature of the study, conducted on anonymized records (Privacy guarantor act, GU 1st March 2012, n. 72).

\section{Results}

The study population included 2,492 patients with diagnosis of sepsis: the mean age was 77.9 (SD 14.6), with 1 , 319 cases $(52.9 \%) \geq 80$ years. The characteristics of patients in relation to age groups are summarized in Table 1. The proportion of men (total 1,355 (54.4\%)) increased in relation to age groups: $48.2 \%$ in subjects $<80$ years vs. $51.8 \%$ in subjects $\geq 80$ (OR $1.1095 \%$ CI $1.03-1.189$; $\mathrm{P}=$ $0.006)$. Over time, the number of subjects $\geq 80$ doubled from 245 (2009-2010) to 484 (2015-2016), but no significant difference in percentage was observed $(52.0 \%$, $95 \% \mathrm{CI} 47.4 \%-56.4 \%(2009-2010)$ vs. $54.4 \%(95 \% \mathrm{CI}$ $51.1 \%-57.6 \%)(2015-2016) ; \mathrm{p}=0.876)($ Table 1$)$.

Main comorbidities were COPD (45.8\%), cancer (42.0\%), AHF (35.5\%) CKD (33.6\%), dementia (30.1\%) and diabetes (29.2\%), with COPD, diabetes, AHF, CKD, and dementia more represented in the group of subject $\geq 80$ (Table 1). The SIRS score at entry in the ED was $\geq 2$ in $75.4 \%$ of cases; ED waiting time was 60 min (SD 82): no differences between age groups were observed (Table 1).

The diagnosis of sepsis was suspected only in $32.9 \%$ of cases at admission (Table 1). The most common serious infection diagnoses occurred in the respiratory system (64.1\%) and in the genitourinary tract (26.4\%), with respiratory system infections more represented in subjects $\geq 80$ years $(72.6 \%$ vs. $54.6 \%$; OR $2.2095 \%$ CI $1.86-2.60$; $\mathrm{P}=0.001$ ) (Table 2). The organ/system dysfunction diagnoses more frequently observed were cardiovascular failure $(27.1 \%)$, acute respiratory failure $(57.8 \%)$ and renal failure (17.4\%), cardiovascular failure and acute respiratory failure. These last two comorbidities were also more common in subjects $\geq 80$ (30.0\% vs. $24.0 \%$, OR 1.36 $95 \%$ CI $1.14-1.63$; $\mathrm{P}<0.001$, and $57.8 \%$ vs. $46.2 \%$ OR 1.60 95\%CI $1.36-1.87 ; \mathrm{P}=0.001$, respectively) (Table 2).

Blood culture positive rates were recorded in $29.8 \%$ of total cases, with reduced rates in subjects $\geq 80$ : anaerobic agents were most commonly represented (14.4\%) (Additional file 1: Table S1). ED length of stay was 246 (SD 678) min and median hospital length of stay was 10 [IQR 14] days (6 [12] in subjects who died, 11 [12] in subjects discharged), without differences in relation to age groups.

The incidence rate (number of sepsis-related admissions per 100 total hospital admissions) increased from $3.8 \%$ (2009-2010) to $4.7 \%(2015-2016) ; P<0.001$.
This increase was especially observed in subjects $\geq 80$ (Additional file 2: Table S2).

A total of 687 patients died (27.6\%). Overall CFR decreased from $31.8 \%$ (95\%CI $27.7 \%$ - 36.1\%) (2009-2010) to $25.0 \%(95 \%$ CI $22.2 \%-27.9 \%)(2015-2016)(P=0.007)$, with a downward trend in the calendar year periods $(\mathrm{P}<$ 0.003). We observed no difference in the percentage of subjects aged $\geq 80$ who died: $52.9 \%(2009-2010)$ vs. $54.4 \%$ (2015-2016); $P=0.156$.

In the building model 10 items, out of the 27 tested, entered as outcome predictors (Table 3). Analytical and graphical methods showed that the proportionality assumption of the model was not violated (not reported in details) and the final model showed an overall accuracy (Area Under the Curve) of $0.848 \pm$ SE 0.015; P $<0.001$. The overall accuracy of the model was confirmed in the validation dataset (Area Under the Curve) of $0.873 \pm \mathrm{SE}$ 0.009; $\mathrm{P}<0.001$ (not different from the building cohort; DeLong test). The distribution of CFR according to risk score percentiles (deciles) in the entire population, grouped according to age, is reported in Fig. 1.

When stratified by the risk score CFR decreased (from $13.3 \%(95 \% \mathrm{CI} 9.8 \%-17.4 \%)$ to $5.2 \%(95 \% \mathrm{CI}$ $3.5 \%-7.2 \%) ; P<0.001)$ in the low risk group. A progressive decline in CFR was confirmed both in the group of subjects $\geq 80$ years, where it decreased from $18.2 \%(95 \% \mathrm{CI} 12.2 \%-25.2 \%)$ to $6.6 \%(95 \% \mathrm{CI} 4.1 \%$ $10.0 \%)(P=0.003)$ (Fig. 2) and in the group of subjects aged $<80$ from $9.7 \%(95 \%$ CI $5.9 \%-14.6 \%)$ to $3.9 \%(95 \% \mathrm{CI} 2.1 \%-6.4 \%)(P=0.010)$. In the total high-risk cohort, CFR was very high and did not change in the course of the years $66.9 \%(95 \% \mathrm{CI}$ $59.0 \%-73.3 \%)$ in 2009 and $62.5 \%$ (95\%CI $56.8 \%$ -

Table 3 Predictors of case fatality rate in subjects with sepsis related hospitalizations by variables included in the logistic model

\begin{tabular}{llll}
\hline Variables & Odds Ratio & $95 \% \mathrm{Cl}$ & $P$ value \\
\hline ICU admission & 15.03 & $7.33-30.81$ & $<0.001$ \\
Cardio-vascular dysfunction & 13.53 & $9.94-18.43$ & $<0.001$ \\
HIV & 10.94 & $3.75-31.93$ & $<0.001$ \\
Diabetes & 3.01 & $2.35-3.85$ & $<0.001$ \\
Age $\geq 80$ years & 2.32 & $1.79-3.10$ & $<0.001$ \\
Respiratory diseases & 2.17 & $1.60-2.94$ & $<0.001$ \\
Digestive diseases & 1.93 & $1.27-2.93$ & 0.002 \\
Dementia & 1.82 & $1.43-2.34$ & 0.001 \\
No. of organ dysfunction & 1.62 & $1.27-2.06$ & $<0.001$ \\
Cancer & 1.48 & $1.17-1.88$ & 0.001 \\
\hline
\end{tabular}

Variables not included in the model: sex, mode of arrival in ED, the score criteria of Systemic Inflammatory Response syndrome (SIRS), infectious parasitic disease, nervous, circulatory and genitourinary diseases diagnoses, COPD, CKD, Charlson index, hematologic, neurologic, renal, respiratory and hepatic dysfunction, and ED waiting time, ED length-of-stay, as dichotomized variables. Data are reported as odds ratio and $95 \%$ confidence intervals $(\mathrm{Cl})$ 


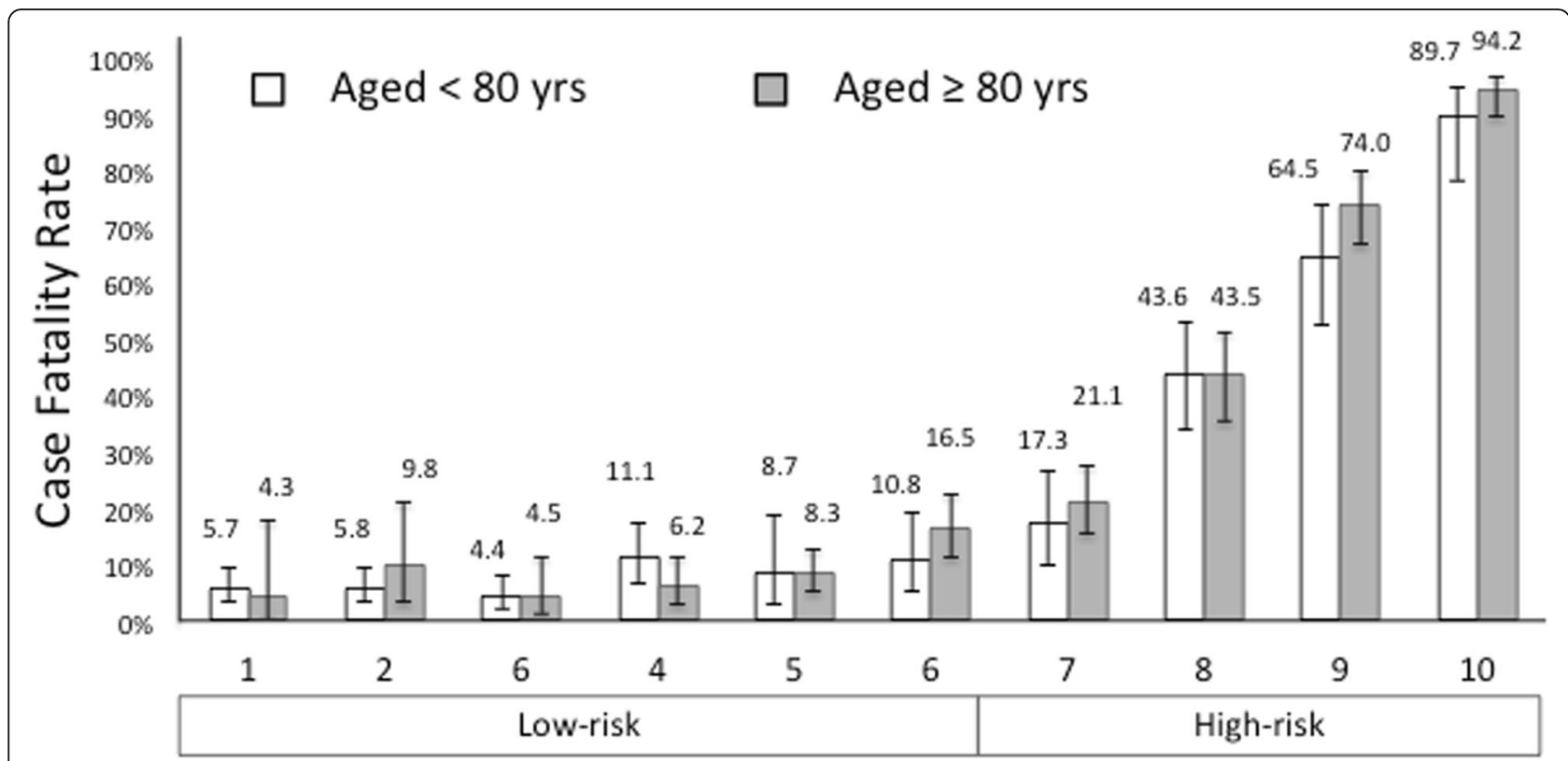

Fig. 1 Proportion of case fatality rate (CFR) (median and 95\% confidence intervals) by deciles of risk score and by age in subjects with sepsis related hospitalizations. Open columns represent CFR in subjects aged $<80$, grey columns are subjects $\geq 80$

$67.6 \%)$ in 2016; $p=0.743$. This was also the case of subjects aged <80: $60.0 \%(95 \% \mathrm{CI} 45.2 \%-71.5 \%)$ to $58.9 \%(95 \%$ CI $48.4 \%-67.8 \%) ; P=0.972$, and of subjects $\geq 80$ : $69.9 \%(60.4 \%-77.2 \%)$ to $64.2 \%(95 \% \mathrm{CI}$ $60.4 \%-57.3 \%-70.1 \%): P=0.713$ (Fig. 2)

\section{Discussion}

The study provides three important messages: first, it confirms an increasing incidence of hospital admission with diagnosis of sepsis between 2009 and 2016; the incidence is largely driven by a more frequent occurrence

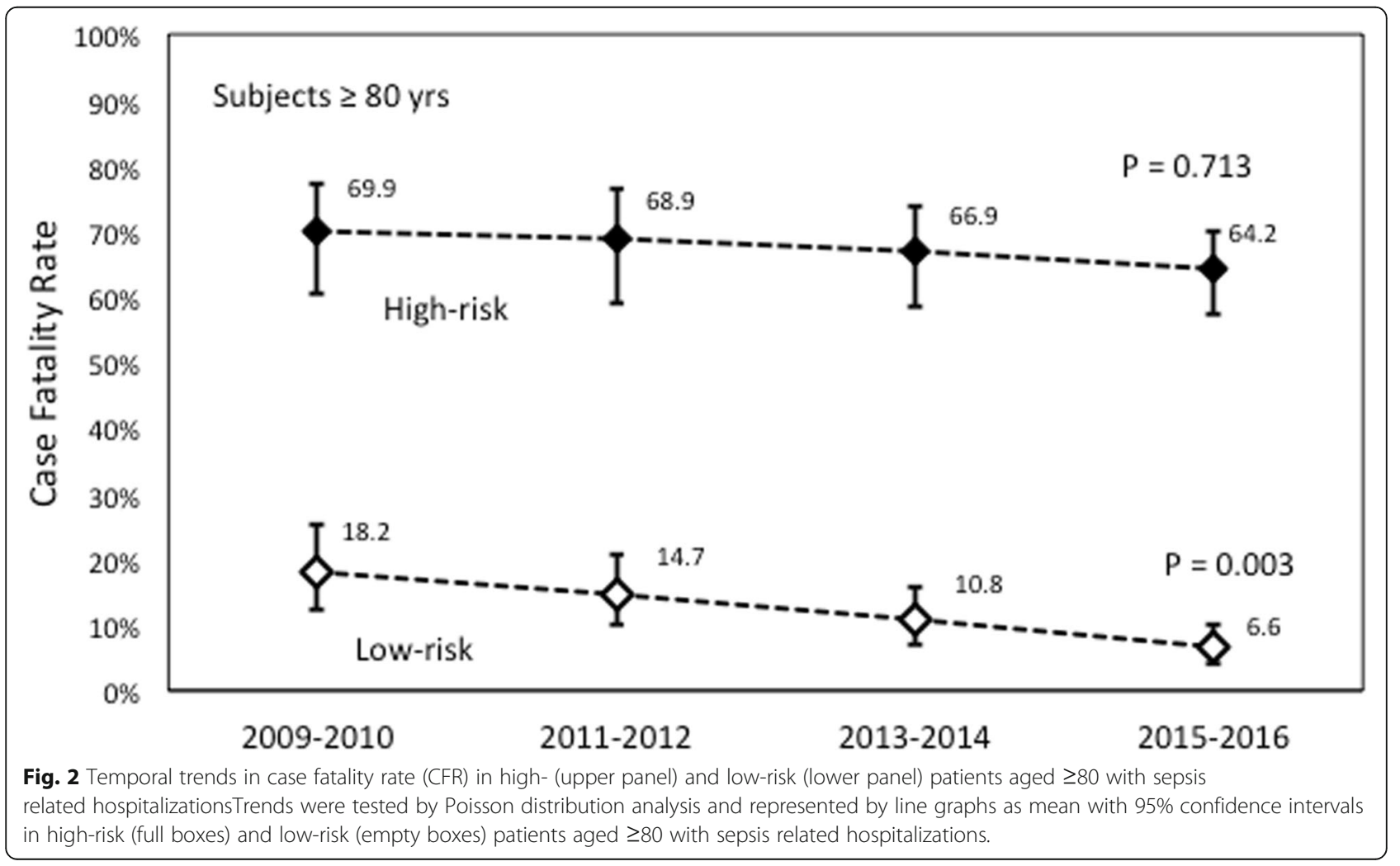


in subjects $\geq 80$ years; the CFR is declining, but this reduction is mainly limited to the elderly low-risk cohort. Finally, a group of 10 main predictors, i.e., older age, comorbidities, cardio-vascular dysfunction, number of organ dysfunctions and ED length-of stay predicted case fatality rate with good accuracy.

The incidence of sepsis has been reported to increase with age, mainly due to a sharp incidence in the group of subjects aged $\geq 80$ [5], with high mortality rate [12-14]. In a recent large study nearly two thirds of patients admitted for sepsis were aged 65 or older [15] with age clearly associated with the development of sepsis. Our data probably reflect the peculiar Italian demography, with $84 \%$ of our patients over 65 and $53 \%$ over 80 .

An increased incidence of cases with sepsis might be influenced by the combined effect of "up-coding diagnosis" and concurrent organ dysfunction diagnoses code. The first condition might stem from the diffusion of international guidelines of the surviving sepsis campaign [16], which leads to classify patients with serious infection as having sepsis; the second factor adds new diagnoses to the cases with diagnosis codes of sepsis/septic shock. Both effects are very likely to occur in low-risk cases and in older subject [17]. In our series, the number of sepsis diagnoses increased from 2009 to 2016, the relative percentage of low- vs. high-risk cases did not change over time, but mortality only decreased in low-risk patients. This finding is well in keeping with a possible effect of the surviving sepsis campaign, but also indicates that we could effectively improve the outcome only in less severe cases.

Our dataset captures all acute care hospitalizations for sepsis by ICD-9 codes. This method is currently accepted in sepsis epidemiology for assessing the main characteristics and trends for health care planning $[2,4]$. Our study is based upon a hospital database, and the registration of organ dysfunction did not change over time; given the universalistic nature of the Italian health system, where coding practices are not conditioned by economic incentives, there is a low-risk of selection bias. The increased number of diagnosis code of sepsis is likely to stem from both increased awareness and knowledge among physicians, as well as a systematic upcoding driven by surviving sepsis campaigns [2].

Reduced mortality might also be associated with an increased up-coding effect, considering changes in diagnostic criteria ("serious infection associated with organ failure" adding to the sole "sepsis/septic shock") $[18,19]$. In our series we considered the novel criteria throughout the observation period, and the up-coding effect should be reduced to a minimum [18].

Considering the wide variability of the demographic and clinical characteristics of subjects with sepsis, several prognostic models were derived using different sets of variables. In a recent study a group of variables, i.e. age, the modified APACHE II score, ICU length of stay, patient location at sepsis diagnosis and coagulopathy were indicated as main outcome predictors [15]; in another study the selected variables entering the logistic model were only those associated with immediate fatality conditions, severity score or condition warranting intensive care admission and frailty, but not age [20,21].

In our model, the area under the ROC curve (0.873) confirmed the validity of the logistic model, with selected variables indicating the patients' clinical profile, serious infection and organ dysfunction diagnoses, not the early warning score for detection (SIRS score $\geq 2$ ) at ED entry, which was positive in only $2 / 3$ of cases. Other scores compete with SIRS as warning tools for the early detection of sepsis, but do not predict the mortality. Although not operative in our setting, we calculated a posteriori the qSOFA as another potential predictor of sepsis at entry [6]. The score, based on a combination of abnormal mental status, respiratory rate and systolic blood pressure, was positive (>1) in $92.4 \%$ of cases, but did not enter the logistic regression when added to the model instead of SIRS, in keeping a higher sensitivity of qSOFA compared with SIRS [22].

The selected variables might be associated with different risk profile, in relation to the varying pattern of comorbidities in individual patients. This is definitely the case of the positive association between CFR and ICU admission, which is likely to be driven by severity and frailty. In our study mean age was 78 years and the comorbidities included in the logistic model were diabetes in $29 \%$, cancer in $42 \%$, dementia in $30 \%$, HIV in a limited $1.0 \%$ of cases. Our case mix is very different compared with two recently published studies: in one study mean age was 67 years, with diabetes (35\%), dementia (16\%), cancer (24\%) as principal comorbidities [23] and in another study mean age was 49 years, with diabetes present only in $12 \%$, cancer in $14 \%)$, dementia in $0.4 \%$ [2].

Life sustaining treatment limitations in older subjects before the decision to admit patients to intensive care unit might further explain different results, since physicians might be reluctant to admit old patients to ICU despite proper admission criteria [24]. In our study patients admitted to ICU were $4 \%$, with $1.5 \%$ over 80 years, and $1 \%$ over 90 years, a different result in comparison to $8.8 \%$ of cases, with only $0.4 \%$ over 90 years in a recent study [15]: this selection bias might explain part of inequalities of subjects included in different studies.In the last decade large epidemiological studies reported a downward trend of mortality in patients with sepsis, also in the elderly [25]. In a nationwide study in Taiwan the proportion of medical and surgical admissions for sepsis increased from $3.9 \%$ (2002) to 9.4\% (2012) with inhospital mortality rate decreasing from 24.1 to14.8\% [5]; in detail, mortality rate decreased by $24 \%$ in subjects 
aged $65-84$ and by $22 \%$ in the cohort of subjects $>84$ years [2]. Such results were confirmed in a recent, retrospective, nation-wide Spanish study, where the percentage of hospital admissions due to sepsis increased from 3.6 to $5.8 \%$ and the case fatality rate decreased from 19.0 to $17.9 \%$, with mortality rate highest in patients $>85$ years. In these studies, in older subjects no risk score for disease severity was available and the increase in mortality was generally associated with high comorbidity rates, organ failure and high disease severity. In our series after stratification for the risk score, mortality rate over time decreased, and the downward trend in low-risk subjects occurred irrespective of the age cut-off of 80 years.

In a retrospective study a steadily increased mortality has been reported in middle-aged (45-64 years), compared to old (65-74 years) and very old ICU patients (> 75 years) [26], with rates increasing from 42.9 to $49.1 \%$ and to $56 \%$, respectively. In our study CFR in subjects $\geq 80$ was as high as $35.6 \%$, but the range was extremely wide in relation to the risk score. When stratified by the risk score, in the entire cohort CFR was as low as $11.2 \%$ in low-risk subjects (range, 9.1\% - 13.\%) compared to the high-risk individuals (68.6\%, range 64.6-72.2\%).

Limitations: first, although we included a comprehensive set of diagnostic codes of infectious disease to define sepsis, the incidence of sepsis in the elderly population might be nonetheless underestimated. Because of immune failure and functional decline, conventional clinical symptoms of inflammatory response may be lacking in older patients, or they might occur with atypical manifestations, like delirium or falls [27], which are frequent confounders for the rapid diagnosis of sepsis. Second, we used the all-cause mortality rather than sepsisrelated mortality as primary endpoint of our study. A potential bias by indication may arise because older patients are also more likely to die for cardio-vascular and respiratory diseases. Third, a greater awareness of the putative severity of sepsis might drive an increased hospital admission. As with other metrics, if an increasing number of less sick patients is diagnosed with sepsis, CFR is expected to decrease [17]. Notably, only one third of cases were correctly classified as sepsis at entry in ED. Fourth, the analysis was based on a single center cohort, which may limit the external validity of the results (but increases the consistency of diagnostic procedures). Fifth, the study did not directly ascertain the sepsis mortality that might occur after hospital discharge. Finally, the severity of sepsis was not assessed by the appropriate SOFA (Sequential Organ Failure Assessment) score at entry [28], because of the retrospective nature of our chart review analysis and lack of important variables such as the time of onset of the clinical picture. On the other hand such approach made it possible to include consecutive patients, avoiding non-random selection.

\section{Conclusion}

The incidence of hospital admission with diagnosis of sepsis is definitely increasing in the Italian healthcare system, with a downward trend in case fatality rate, also in very old subjects. This positive result, however, remains limited to low-risk subjects.

\section{Supplementary information}

Supplementary information accompanies this paper at https://doi.org/10. 1186/s12877-019-1384-8.

Additional file 1: Table S1. Characteristics and outcome measures of subjects with sepsis related hospitalizations from 2009 to 2016. Data are reported as number of cases (\%).

Additional file 2: Table S2. Trends of incidence in 2492 subjects with sepsis related hospitalizations in the calendar periods between 2009 and 2016. Incidence is reported as number of events/100 admissions in the whole cohort and in different age groups.

\section{Abbreviations}

AHF: History of acute heart failure; CFR: Case fatality rate; CKD: Chronic kidney disease; COPD: Chronic obstructive pulmonary disease; DM: Diabetes mellitus; ED: Emergency Department; ICU: Intensive care unit; qSOFA: quick Sequential Organ Failure Dysfunction; ROC: Receiver operating characteristic; SIRS: Systemic Inflammatory Response syndrome

\section{Acknowledgements}

We are grateful to AUSL Romagna for helpful support.

\section{Authors' contributions}

AF had full access to all of the data in the study and take responsibility for the integrity of the data and the accuracy of the results. All authors were involved in the study concept and design and statistical analyses. BB, AM and $\mathrm{CB}$ were responsible for collection, management, analyses and interpretation of the data. AF, GM, SGR and DM conducted the statistical analyses and drafted the manuscript. All authors contributed substantially to its revision and agree to be accountable for all the aspects of the work. AF takes responsibility for the paper as a whole. All authors read and approved the final manuscript

\section{Funding}

No external funding was received for this study.

\section{Availability of data and materials}

The datasets generated during and/or analyzed during the current study are available from the corresponding author on reasonable request.

Ethics approval and consent to participate

The study was approved by the ethical committee of CEROM Romagna, Italy (2299/2019/O/OssN, January 16, 2019).

Consent for publication

Not applicable.

Competing interests

The authors declare that they have no competing interests

\section{Author details}

${ }^{1}$ Emergency Department, Presidio Ospedaliero Morgagni-Pierantoni, AUSL della Romagna, via C. Forlanini 34, 47121 Forli, FC, Italy. ${ }^{2}$ Department of Medical and Surgical Sciences, "Alma Mater" University, S. Orsola-Malpighi Hospital, Via Massarenti 9, I-40138 Bologna, Italy. ${ }^{3}$ Department of Computer Science and Engineering, Alma Mater University, Mura Anteo Zamboni 7 40127 Bologna, Italy. ${ }^{4}$ Healthcare Management Unit, Presidio Ospedaliero Morgagni-Pierantoni, AUSL della Romagna, via C. Forlanini 34, 47121 Forlì, FC, Italy. ${ }^{5}$ Qatar Computing research Institute (QCRI), HBKU, Doha, Qatar. 
Received: 17 June 2019 Accepted: 12 December 2019

Published online: 23 December 2019

\section{References}

1. Hantrakun V, Somayaji R, Teparrukkul P, Boonsri C, Rudd K, Day NPJ, et al. Clinical epidemiology and outcomes of community acquired infection and sepsis among hospitalized patients in a resource limited setting in Northeast Thailand: a prospective observational study (Ubon-sepsis). PLoS One. 2018;13:e0204509.

2. Lee SH, Hsu TC, Lee MG, Chao CC, Lee WC, Lai CC, et al. Nationwide trend of Sepsis: a comparison among octogenarians, elderly, and young adults. Crit Care Med. 2018;46:926-34.

3. Fleischmann C, Scherag A, Adhikari NK, Hartog CS, Tsaganos T, Schlattmann P, et al. Assessment of global incidence and mortality of hospital-treated Sepsis. Current estimates and limitations. Am J Respir Crit Care Med. 2016:193:259-72.

4. Gaieski DF, Edwards JM, Kallan MJ, Carr BG. Benchmarking the incidence and mortality of severe sepsis in the United States. Crit Care Med. 2013;41:1167-74.

5. Meyer N, Harhay MO, Small DS, Prescott HC, Bowles KH, Gaieski DF, et al. Temporal trends in incidence, Sepsis-related mortality, and hospital-based acute care after Sepsis. Crit Care Med. 2018:46:354-60.

6. Singer M, Deutschman CS, Seymour CW, Shankar-Hari M, Annane D, Bauer $M$, et al. The third international consensus definitions for Sepsis and septic shock (Sepsis-3). JAMA. 2016;315:801-10.

7. Nelson JL, Smith BL, Jared JD, Younger JG. Prospective trial of real-time electronic surveillance to expedite early care of severe sepsis. Ann Emerg Med. 2011:57:500-4.

8. Gagne JJ, Glynn RJ, Avorn J, Levin R, Schneeweiss S. A combined comorbidity score predicted mortality in elderly patients better than existing scores. J Clin Epidemiol. 2011;64:749-59.

9. Shankar-Hari M, Phillips GS, Levy ML, Seymour CW, Liu VX, Deutschman CS, et al. Developing a new definition and assessing new clinical criteria for septic shock: for the third international consensus definitions for Sepsis and septic shock (Sepsis-3). JAMA. 2016;315:775-87.

10. Angus DC, Linde-Zwirble WT, Lidicker J, Clermont G, Carcillo J, Pinsky MR. Epidemiology of severe sepsis in the United States: analysis of incidence, outcome, and associated costs of care. Crit Care Med. 2001;29:1303-10.

11. Iwashyna TJ, Odden A, Rohde J, Bonham C, Kuhn L, Malani P, et al. Identifying patients with severe sepsis using administrative claims: patientlevel validation of the angus implementation of the international consensus conference definition of severe sepsis. Med Care. 2014;52:e39-43.

12. Yang Y, Yang KS, Hsann YM, Lim V, Ong BC. The effect of comorbidity and age on hospital mortality and length of stay in patients with sepsis. J Crit Care. 2010;25:398-405.

13. Martin GS, Mannino DM, Moss M. The effect of age on the development and outcome of adult sepsis. Crit Care Med. 2006;34:15-21.

14. Nasa $P$, Juneja $D$, Singh $O$, Dang $R$, Arora $V$. Severe sepsis and its impact on outcome in elderly and very elderly patients admitted in intensive care unit. J Intensive Care Med. 2012;27:179-83.

15. Martin-Loeches I, Guia MC, Vallecoccia MS, Suarez D, Ibarz M, Irazabal M, et al. Risk factors for mortality in elderly and very elderly critically ill patients with sepsis: a prospective, observational, multicenter cohort study. Ann Intensive Care. 2019;9:26.

16. De Backer D, Dorman T. Surviving Sepsis guidelines: a continuous move toward better Care of Patients with Sepsis. JAMA. 2017:317:807-8.

17. Alvaro-Meca A, Jimenez-Sousa MA, Micheloud D, Sanchez-Lopez A, Heredia-

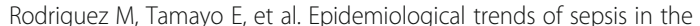
twenty-first century (2000-2013): an analysis of incidence, mortality, and associated costs in Spain. Popul Health Metrics. 2018;16:4.

18. Walkey AJ, Lagu T, Lindenauer PK. Trends in sepsis and infection sources in the United States. A population-based study. Ann Am Thorac Soc. 2015;12:216-20.

19. Rhee C, Gohil S, Klompas M. Regulatory mandates for sepsis care--reasons for caution. N Engl J Med. 2014;370:1673-6.

20. Boumendil A, Angus DC, Guitonneau AL, Menn AM, Ginsburg C, Takun K, et al. Variability of intensive care admission decisions for the very elderly. PLoS One. 2012;7:e34387.

21. Flaatten $H$, De Lange DW, Morandi A, Andersen FH, Artigas A, Bertolini G, et al. The impact of frailty on ICU and 30-day mortality and the level of care in very elderly patients ( $>/=80$ years). Intensive Care Med. 2017;43:1820-8.

22. Raith EP, Udy AA, Bailey M, McGloughlin S, Maclsaac C, Bellomo R, et al. Prognostic accuracy of the SOFA score, SIRS criteria, and qSOFA score for in-hospital mortality among adults with suspected infection admitted to the intensive care unit. JAMA. 2017:317:290-300.

23. Cheng HH, Chen FC, Change MW, Kung CT, Cheng CY, Tsai TC, et al. Difference between elderly and non-elderly patients in using serum lactate level to predict mortality caused by sepsis in the emergency department. Medicine (Baltimore). 2018;97:e0209.

24. Garrouste-Orgeas M, Boumendil A, Pateron D, Aergerter P, Somme D, Simon $T$, et al. Selection of intensive care unit admission criteria for patients aged 80 years and over and compliance of emergency and intensive care unit physicians with the selected criteria: an observational, multicenter, prospective study. Crit Care Med. 2009;37:2919-28.

25. Stevenson EK, Rubenstein AR, Radin GT, Wiener RS, Walkey AJ. Two decades of mortality trends among patients with severe sepsis: a comparative metaanalysis*. Crit Care Med. 2014;42:625-31.

26. Blot S, Cankurtaran M, Petrovic M, Vandijck D, Lizy C, Decruyenaere J, et al. Epidemiology and outcome of nosocomial bloodstream infection in elderly critically ill patients: a comparison between middle-aged, old, and very old patients. Crit Care Med. 2009;37:1634-41.

27. Caterino JM, Kline DM, Leininger R, Southerland LT, Carpenter CR, Baugh CW, et al. Nonspecific symptoms lack diagnostic accuracy for infection in older patients in the emergency department. J Am Geriatr Soc. 2019;67:484-92.

28. Vincent J , de Mendonca A, Cantraine F, Moreno R, Takala J, Suter PM, et al. Use of the SOFA score to assess the incidence of organ dysfunction/failure in intensive care units: results of a multicenter, prospective study. Working group on "sepsis-related problems" of the European Society of Intensive Care Medicine. Crit Care Med. 1998;26:1793-800.

\section{Publisher's Note}

Springer Nature remains neutral with regard to jurisdictional claims in published maps and institutional affiliations.

Ready to submit your research? Choose BMC and benefit from:

- fast, convenient online submission

- thorough peer review by experienced researchers in your field

- rapid publication on acceptance

- support for research data, including large and complex data types

- gold Open Access which fosters wider collaboration and increased citations

- maximum visibility for your research: over $100 \mathrm{M}$ website views per year

At $\mathrm{BMC}$, research is always in progress.

Learn more biomedcentral.com/submission 